\title{
Prognostic Factors Associated with Mortality in Cirrhotic Patients with Bleeding Varices
}

\author{
Alshaimaa Fathy Eldesouky ${ }^{1}$ Mohamed Abd Elraoof Tawfik ${ }^{2}$ Maha Mahmoud Hagras ${ }^{3}$ \\ Taher Eldemerdash Attia ${ }^{1}$ Mohammed Elsayed Elhendawy ${ }^{1, \odot}$
}

${ }^{1}$ Department of Tropical Medicine and Infectious Diseases, Tanta University, Tanta, Egypt

2Department of Internal Medicine, Tanta University, Tanta, Egypt

${ }^{3}$ Department of Clinical Pathology, Tanta University, Tanta, Egypt

Int J Recent Surg Med Sci 2019;5:46-52

\begin{abstract}
Address for correspondence Mohammed Elsayed Elhendawy, MD, Department of Tropical Medicine and Infectious Diseases, Faculty of Medicine, Tanta University, El-Giash Street, Tanta 31527, Egypt (e-mail: mohamed.elhendawy@med.tanta.edu.eg).
\end{abstract}

\begin{abstract}
Keywords

- liver cirrhosis

- variceal bleeding

- mortality

- encephalopathy

Objective Bleeding gastroesophageal varices are a cause of high mortality among cirrhotic patients. The aim of this study was to study prognostic factors for mortality in cirrhosis associated with variceal bleeding.

Patients and Methods This prospective study was conducted on 100 cirrhotic patients admitted to the Tanta University Hospital with an acute first variceal bleeding episode. Baseline clinical, laboratory, and endoscopic findings were recorded at presentation.

Results During the first 6 weeks 15 patients died, 3 following the initial bleed and 12 after an early rebleed. At 6 months, a further 21 patients had died. Statistical analysis utilizing the baseline data revealed that high early death rate was associated with number of blood units transfused, lower systolic blood pressure, thrombocytopenia, increased serum creatinine and international normalized ratio (INR). High MELD, AIMS56, acute physiology and chronic health evaluation II (APACHE II) and ROCKall scores were risk factors for mortality. Risk factors for early rebleeding included presence of diabetes mellitus, leucocytosis, high Child score, model for end-stage liver disease (MELD), AIMS56, and sepsis-associated organ failure assessment (SOFA) scores. A high Child score, presence of ascites, and associations such as hepatic encephalopathy and spontaneous bacterial peritonitis, leucocytosis, elevated alanine transaminase, aspartate transaminase, bilirubin, INR, and creatinine as well as low albumin were associated with decreased survival.

Conclusion High MELD, AIMS56, APACHE II, and ROCKall scores were risk factors for mortality after acute variceal bleeding. High death rate during the first 6 weeks is associated with anemia, hypotension, thrombocytopenia, increased serum creatinine, and INR. Decreased survival at 6 months is associated with increased Child score, presence of ascites and associations such as hepatic encephalopathy and spontaneous bacterial peritonitis.
\end{abstract}

\section{Introduction}

Upper gastrointestinal bleeding (UGIB) is the loss of blood through the GI tract originating proximal to the Treitz angle. ${ }^{1}$ Acute hemorrhage from varices is one of most menacing portal hypertension complications and related to
DOI https://doi.org/ $10.1055 / \mathrm{s}-0039-3400619$ ISSN 2455-7420. high morbidity and mortality. ${ }^{2}$ The prognosis of cirrhotic patients is related to severity of the hepatic condition liver which could be assessed using the Child-Turcotte-Pugh (CTP) classification, with higher scores having a significant impact on survival times. ${ }^{3}$ 
Portal hypertension leads to the development of portosystemic collateral venous vessels. Every year 5 to $10 \%$ of patients with cirrhosis will develop esophageal varices. ${ }^{4}$ This is more likely to occur in patients with progressive cirrhosis and may be present in up to $60 \%$ of patients with decompensated cirrhosis. ${ }^{5}$

Mortality rates following a first variceal bleed in cirrhotics increase with advancement of the Child score and range between 15 and 80\%. ${ }^{6}$ The main causes of death are unstoppable hemorrhage, infection and kidney failure. There are multiple determinants linked to increased mortality and poor prognosis including high MELD scores, kidney failure, hepatic venous pressure gradients above $20 \mathrm{~mm} \mathrm{Hg}$, and evidence of an active bleed on endoscopy. ${ }^{7,8}$

It is uncertain if the currently used prognostic scores, namely the CPT and MELD scores are reliable in determination of acute variceal hemorrhage risk.

The aim of the current study was to identify the prediction model most suitable for determining the outcome of acute variceal bleeding.

\section{Patients and Methods}

This study was a prospective study performed on 310 patients with upper gastrointestinal tract bleeding, 210 were excluded and 100 were included from October 2017 to December 2018. They were collected from Tropical Medicine Department and Internal Medicine Department, Tanta University Hospital.

\section{Inclusion criteria:}

- Cirrhotic patients with bleeding varices (esophageal, fundal, or both).

Exclusion criteria:

- Patients with hepatocellular carcinoma (HCC).

- Patients with upper GI hemorrhage due to causes other than ruptured varices (peptic ulcers and erosions, esophagitis, malignant masses, and vascular ectasia).

The study was approved by the ethical review board, Tanta University, Faculty of Medicine, with approval code $31779 / 09 / 2017$. All patients participating in the study provided a signed informed consent. The study protocol abides by the guidelines of the Declaration of Helsinki 1975 guidelines and was approved by the faculty's human research committee.

A meticulous history was taken from all patients and they were subjected to thorough examination and monitoring. All relevant laboratory tests were performed including baseline and serial liver function tests and serum creatinine. Blood counts, electrolyte, and arterial blood gas levels, as well as amounts of blood transfused were recorded. An upper GI endoscopy was done to diagnose the cause of bleeding and enable making appropriate treatment decisions. All the patients underwent abdominal ultrasonography.

The recorded baseline data were used to calculate various prognostic scores including CTP, MELD, APACHE II (acute physiology and chronic health evaluation II), AIMS65, sepsis-associated organ failure assessment (SOFA) and the ROCKall scores.

The primary end point: survival and rebleeding within 6 weeks after the first variceal bleeding attack.

The secondary end point: survival for 6 months after the first variceal bleeding attack.

\section{Statistical Analysis}

Mean, standard deviation, Student's $t$-test, and chi-square test were performed by Statistical Package for Social Sciences (IBM SPSS StatisticsVersion 20) and receiver operating characteristic (ROC) curve.

\section{Results}

This study was a prospective study performed on 310 patients with upper GIT bleeding presented to Tanta University Hospital: 210 patients had been excluded (either refused or not met the inclusion criteria) and 100 patients had been included from October 2017 to December 2018. After the first attack of bleeding 85 patients lived and 15 patients died; after 6 months 64 patients were survivors and 21 did not survive. Total deaths after 6 months were 36 patients ( - Fig. $\mathbf{1}$ ).

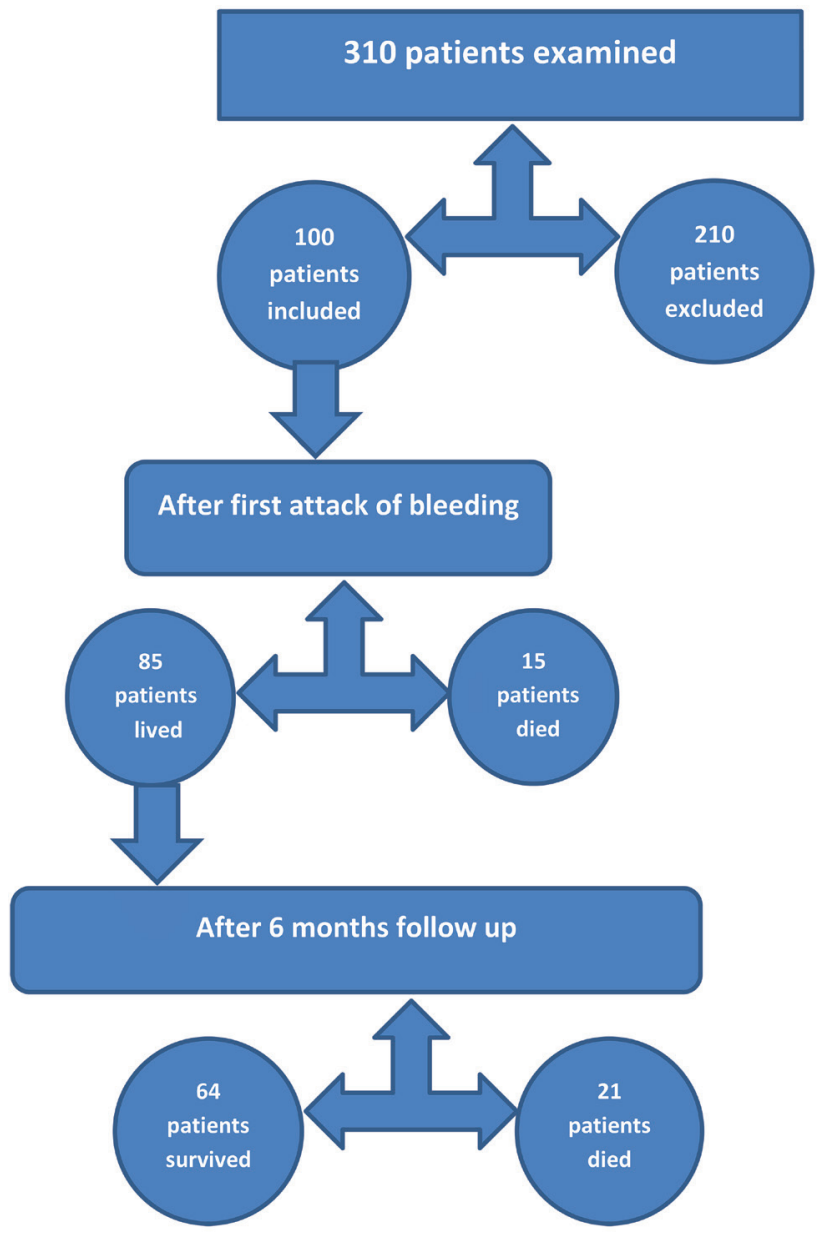

Fig. 1 Study analysis population. 
Risk Factors for Death After the First Attack of Bleeding After the first attack of bleeding 15 patients died out of total 100 patients enrolled in the study. Regarding age, sex, smoking, presence of ascites, diabetes mellitus, and hypertension there were no statistically significant differences between the patients.

There were significant differences between the studied patients as regards the number of blood units $(p<0.001)$. More the blood units needed, worse the prognosis. There were no significant differences between the studied patients as regards Sungestaken tube inflation before the endoscopy, associations (hepatic encephalopathy, spontaneous bacterial peritonitis, and hepatorenal syndrome), proton pump infusion before endoscopy, and beta blockers intake (-Table $\mathbf{1}$ ).

There was no significant difference between the studied patients as regards the endoscopic findings, variceal grades, and method of intervention.

There was significant difference between the studied patients as regards systolic blood pressure-the lower the systolic blood pressure, the worse the prognosis. Also thrombocytopenia, increased serum creatinine, and INR are risk factors for increased death rate ( $\mathbf{- T a b l e ~} \mathbf{2}$ ).

Significant differences were noted between the studied patients as regards the MELD score, AIMS56 score, APACHE II score, and ROCKall score $(p \leq 0.001)$. Increased MELD, AIMS56, APACHE II, and ROCKall scores were risk factors for mortality. Child score wasn't associated with mortality (-Table 2; -Fig. 2).

AIMS56 score has 92.94 sensitivity, 26.67 specificity, and $57.7 \%$ accuracy.

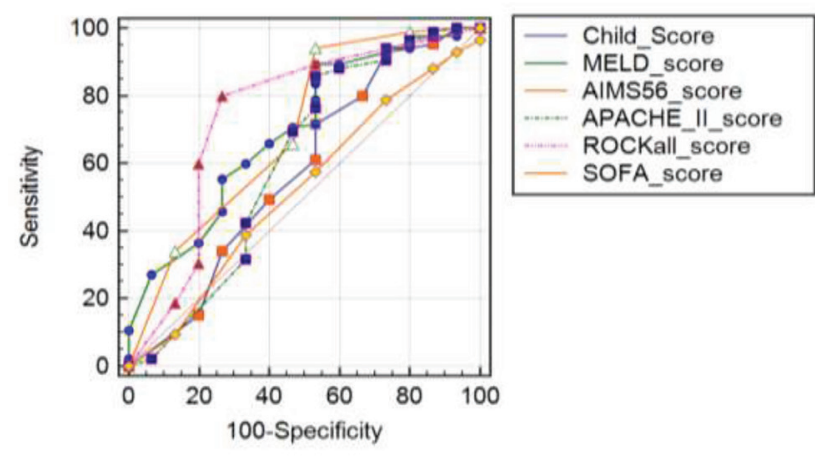

Fig. 2 Receiver operating characteristic curve for scores for outcome after first bleeding attack.

ROCKall score has 80.00 sensitivity, 73.33 specificity, and $74.4 \%$ accuracy. ROCKall score was the most suitable score for predicting mortality after the first attack of bleeding.

\section{Risk Factor of Early Rebleeding Within 6 Weeks After the First Bleeding Attack}

Presence of diabetes mellitus was associated with increased risk of rebleeding (-Table 3 ).

The studied patients differed significantly regarding their systolic blood pressure, alanine transaminase (ALT), aspartate transaminase (AST), WBCs, total bilirubin, serum albumin, INR, and prothrombin activity, serum creatinine and urea, leucocytosis, increased ALT, AST, bilirubin, INR, activity, and serum creatinine.

Table 1 Clinical data in patients first 6 weeks after first attack of bleeding

\begin{tabular}{|c|c|c|c|c|c|c|c|c|c|}
\hline & & \multicolumn{6}{|c|}{ Outcome after first bleeding attack } & \multirow{2}{*}{\multicolumn{2}{|c|}{ Chi-square }} \\
\hline & & \multicolumn{2}{|c|}{ Nonsurvivor } & \multicolumn{2}{|c|}{ Survivor } & \multicolumn{2}{|c|}{ Total } & & \\
\hline & & $N$ & $\%$ & $N$ & $\%$ & $N$ & $\%$ & $\chi^{2}$ & $p$-Value \\
\hline \multirow[t]{3}{*}{ Complaint } & Hematemesis & 7 & 46.67 & 34 & 40.00 & 41 & 41.00 & \multirow[t]{3}{*}{1.194} & \multirow[t]{3}{*}{0.550} \\
\hline & Melena & 3 & 20.00 & 29 & 34.12 & 32 & 32.00 & & \\
\hline & Both & 5 & 33.33 & 22 & 25.88 & 27 & 27.00 & & \\
\hline \multirow{6}{*}{$\begin{array}{l}\text { Number of blood } \\
\text { units }\end{array}$} & No & 7 & 46.67 & 22 & 25.88 & 29 & 29.00 & \multirow[t]{6}{*}{11.291} & \multirow[t]{6}{*}{$0.046^{\mathrm{a}}$} \\
\hline & One & 0 & 0.00 & 30 & 35.29 & 30 & 30.00 & & \\
\hline & Two & 6 & 40.00 & 14 & 16.47 & 20 & 20.00 & & \\
\hline & Three & 1 & 6.67 & 9 & 10.59 & 10 & 10.00 & & \\
\hline & Four & 1 & 6.67 & 9 & 10.59 & 10 & 10.00 & & \\
\hline & Five & 0 & 0.00 & 1 & 1.18 & 1 & 1.00 & & \\
\hline \multirow{2}{*}{$\begin{array}{l}\text { Sungestaken tube } \\
\text { usage }\end{array}$} & No & 14 & 93.33 & 84 & 98.82 & 98 & 98.00 & \multirow[t]{2}{*}{1.961} & \multirow[t]{2}{*}{0.161} \\
\hline & Yes & 1 & 6.67 & 1 & 1.18 & 2 & 2.00 & & \\
\hline \multirow{2}{*}{$\begin{array}{l}\text { Association (SBP, } \\
\text { HRS, HE) }\end{array}$} & No & 5 & 33.33 & 35 & 41.18 & 40 & 40.00 & \multirow[t]{2}{*}{0.327} & \multirow[t]{2}{*}{0.568} \\
\hline & Yes & 10 & 66.67 & 50 & 58.82 & 60 & 60.00 & & \\
\hline \multirow{2}{*}{$\begin{array}{l}\text { Proton pump } \\
\text { infusion }\end{array}$} & No & 0 & 0.00 & 3 & 3.53 & 3 & 3.00 & \multirow[t]{2}{*}{0.546} & \multirow[t]{2}{*}{0.460} \\
\hline & Yes & 15 & 100.00 & 82 & 96.47 & 97 & 97.00 & & \\
\hline \multirow[t]{2}{*}{ Beta blockers } & No & 13 & 86.67 & 67 & 78.82 & 80 & 80.00 & \multirow[t]{2}{*}{0.490} & \multirow[t]{2}{*}{0.484} \\
\hline & Yes & 2 & 13.33 & 18 & 21.18 & 20 & 20.00 & & \\
\hline
\end{tabular}

Abbreviations: HE, hepatic encephalopathy; HRS, hepatorenal syndrome; SBP, spontaneous bacterial peritonitis.

astatistically significant. 
Table 2 Patients scores and laboratory data in first attack of bleeding

\begin{tabular}{|c|c|c|c|c|}
\hline & \multicolumn{2}{|c|}{ Outcome after first bleeding attack } & \multicolumn{2}{|c|}{$t$-test } \\
\hline & Nonsurvivors (mean \pm SD) & Survivors (mean \pm SD) & $T$ & $p$-Value \\
\hline Hemoglobin & $8.413 \pm 1.215$ & $8.482 \pm 1.031$ & 0.233 & 0.817 \\
\hline WBCs & $6.160 \pm 4.577$ & $6.206 \pm 3.904$ & 0.041 & 0.967 \\
\hline Platelets & $135.000 \pm 55.554$ & $104.188 \pm 49.957$ & 2.166 & $0.033^{a}$ \\
\hline ALT & $31.400 \pm 11.306$ & $35.800 \pm 36.419$ & 0.462 & 0.645 \\
\hline AST & $52.533 \pm 17.067$ & $56.812 \pm 28.533$ & 0.562 & 0.576 \\
\hline Bilirubin & $3.467 \pm 4.667$ & $2.339 \pm 2.558$ & 1.364 & 0.176 \\
\hline Albumin & $2.733 \pm 0.623$ & $2.965 \pm 0.474$ & 1.660 & 0.100 \\
\hline INR & $1.593 \pm 0.616$ & $1.339 \pm 0.396$ & 2.090 & $0.039^{a}$ \\
\hline Creatinine & $1.313 \pm 0.558$ & $1.037 \pm 0.352$ & 2.546 & $0.012^{\mathrm{a}}$ \\
\hline Urea & $57.333 \pm 27.105$ & $45.882 \pm 32.298$ & 1.294 & 0.199 \\
\hline Child Score & $8.867 \pm 3.067$ & $8.000 \pm 2.345$ & 1.257 & 0.212 \\
\hline MELD score & $17.600 \pm 7.935$ & $12.682 \pm 5.583$ & 2.938 & $0.004^{a}$ \\
\hline AIMS56 & $2.133 \pm 1.552$ & $1.071 \pm 0.961$ & 3.561 & $0.001^{\mathrm{a}}$ \\
\hline APACHE II & $7.267 \pm 6.147$ & $4.459 \pm 3.194$ & 2.666 & $0.009^{a}$ \\
\hline SOFA score & $3.467 \pm 1.767$ & $3.376 \pm 1.739$ & 0.185 & 0.854 \\
\hline ROCKall & $4.667 \pm 1.839$ & $3.212 \pm 1.544$ & 3.269 & $0.001^{\mathrm{a}}$ \\
\hline
\end{tabular}

Abbreviations: ALT, alanine transaminase; AST, aspartate transaminase; INR, international normalized ratio.

astatistically significant.

Significant differences were recorded as regards Child score, MELD score, AIMS56 score, and Sofa score. Increases Child, MELD, AIMS56, and Sofa scores were risk factors for early rebleeding. No such differences were recorded as regards APACHE II score and ROCKall score.

\section{Factors Affecting Outcome 6 Months After Bleeding}

The studied patients were matched as regards age or sex ( - Table 4). Presence of ascites was associated with decreased survival.

Associations as hepatic encephalopathy and spontaneous bacterial peritonitis were associated with decrease survival.

There were significant differences between the studied patients as regards WBCs, ALT, AST, total bilirubin, direct bilirubin, serum albumin, INR, prothrombin activity, serum creatinine, and urea. Leucocytosis, increased ALT, AST, bilirubin, INR, activity, serum creatinine, and urea decrease albumin associated with decrease survival.

Child scores were significantly different between studied patient groups on the contrary to the MELD score (-Fig. 3).

ROC curve shows that Child score had 65.62 sensitivity, 95.24 specificity, and $88.7 \%$ accuracy, whereas MELD score had 100.00 sensitivity, 21.43 specificity, and 55.5\% accuracy.

\section{Discussion}

Variceal hemorrhage is a complication of cirrhosis that denotes decompensation and that still has a high mortality rate. ${ }^{9}$
Even though management of variceal hemorrhage has improved in the last decades, 6-week mortality following a GI bleed remains high at around 10 to $20 \%$, and rises with advanced cirrhosis. ${ }^{10}$

In this study, there was significant difference between the studied patients as regard blood pressure. Our findings agree with those of Gado et al, ${ }^{11}$ and Jiménez et al. ${ }^{12}$ They found that hemodynamic instability at admission, Child class C, blood in GI tract at the index endoscopy, rebleeding within five days of endoscopy, and in-hospital complications were independent predictors of mortality.

We have detected significant differences between the studied patients as regards associations (hepatic encephalopathy, spontaneous bacterial peritonitis, thrombocytopenia, increase serum creatinine, raised INR, and prolonged prothrombin time), as did Goldis et al. ${ }^{13}$

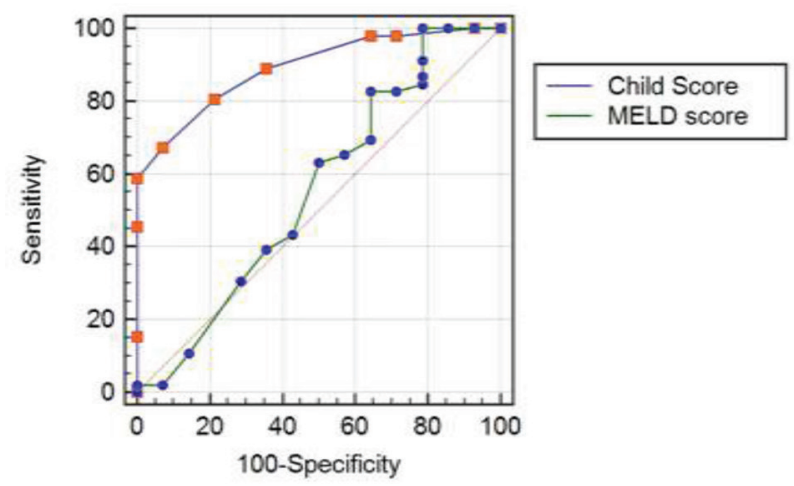

Fig. 3 Receiver operating characteristic curve between MELD and Child scores for 6 months survival. 
Table 3 Clinical and laboratory data in patients with rebleeding

\begin{tabular}{|c|c|c|c|c|}
\hline & Mean \pm SD & Mean \pm SD & $t$ & $p$-Value \\
\hline Age & $58.182 \pm 8.125$ & $56.667 \pm 6.746$ & 0.617 & 0.539 \\
\hline SBP & $108.750 \pm 10.701$ & $99.167 \pm 7.930$ & 2.987 & $0.004^{a}$ \\
\hline DBP & $66.932 \pm 9.512$ & $59.167 \pm 7.930$ & 2.699 & $0.008^{a}$ \\
\hline Hemoglobin & $8.478 \pm 1.084$ & $8.425 \pm 0.841$ & 0.164 & 0.870 \\
\hline Hemoglobin after first & $9.485 \pm 0.798$ & $9.717 \pm 0.610$ & -0.965 & 0.337 \\
\hline WBCs & $5.872 \pm 3.553$ & $8.600 \pm 6.002$ & -2.270 & $0.025^{a}$ \\
\hline Platelets & $109.727 \pm 53.109$ & $102.083 \pm 41.507$ & 0.478 & 0.634 \\
\hline ALT & $31.375 \pm 12.530$ & $62.750 \pm 90.148$ & -3.144 & $0.002^{\mathrm{a}}$ \\
\hline AST & $53.375 \pm 18.906$ & $76.667 \pm 57.105$ & -2.895 & $0.005^{a}$ \\
\hline Total bilirubin & $2.084 \pm 1.437$ & $5.617 \pm 7.131$ & -4.180 & $<0.001^{\mathrm{a}}$ \\
\hline Direct bilirubin & $1.114 \pm 0.869$ & $3.300 \pm 4.375$ & -4.232 & $<0.001^{a}$ \\
\hline Serum albumin & $2.981 \pm 0.485$ & $2.558 \pm 0.487$ & 2.829 & $0.006^{a}$ \\
\hline INR & $1.336 \pm 0.392$ & $1.678 \pm 0.654$ & -2.582 & $0.011^{a}$ \\
\hline Prothrombin activity & $74.244 \pm 18.631$ & $62.000 \pm 23.909$ & 2.062 & $0.042^{\mathrm{a}}$ \\
\hline Serum creatinine & $1.044 \pm 0.372$ & $1.331 \pm 0.508$ & -2.396 & $0.018^{a}$ \\
\hline Urea & $43.886 \pm 26.052$ & $74.833 \pm 52.587$ & -3.328 & $0.001^{\mathrm{a}}$ \\
\hline Child Score & $7.898 \pm 2.344$ & $9.833 \pm 2.791$ & -2.623 & $0.010^{\mathrm{a}}$ \\
\hline MELD score & $12.841 \pm 5.669$ & $17.667 \pm 8.348$ & -2.601 & $0.011^{a}$ \\
\hline AIMS56 score & $1.136 \pm 1.095$ & $1.917 \pm 1.165$ & -2.298 & $0.024^{a}$ \\
\hline APACHE II score & $4.682 \pm 3.564$ & $6.333 \pm 5.662$ & -1.392 & 0.167 \\
\hline SOFA score & $3.193 \pm 1.589$ & $4.833 \pm 2.125$ & -3.215 & $0.002^{\mathrm{a}}$ \\
\hline ROCKall score & $3.409 \pm 1.679$ & $3.583 \pm 1.621$ & -0.339 & 0.736 \\
\hline
\end{tabular}

Abbreviations: ALT, alanine transaminase; AST, aspartate transaminase; DBP, diastolic blood pressure; INR, international normalized ratio; SBP, systolic blood pressure.

aStatistically significant.

No significant differences were recorded as regards proton pump inhibitor (PPI) infusion. This finding was in disagreement with Komori et al, ${ }^{14}$ who found an association between regular PPI treatment before and after the onset of variceal bleeds and increments in short as well as long-term mortalities. This could be explained by the increased risk of infections such as bacterial infections in general and spontaneous bacterial peritonitis following regular PPI use. ${ }^{15,16}$

We detected significant difference between the studied patients as regards MELD score, ROCKall score, and AIMS65 score. This finding was in agreement with Saltzman et $\mathrm{al}^{17}$ and Gado et al. ${ }^{11}$ This finding was in disagreement with Mohammad et al, ${ }^{18}$ who reported the superiority of the SOFA score in mortality prediction when compared with the MELD, APACHEII, and CPT scores and concluded that independently the AIMS65 score was the simplest and most applicable scoring system for mortality prediction among cirrhosis patients suffering from acute variceal hemorrhage.

\section{Early Rebleeding Risk Factors}

We had 12 patients presented with early rebleeding; we found that leucocytosis, increased ALT, AST, bilirubin, INR, prothrombin activity, and serum creatinine and decreased albumin associated with increased risk of rebleeding. This finding was in agreement with Jiménez et al, ${ }^{12}$ who found that low systolic blood pressure, high creatinine, and albumin levels were independent factors associated with rebleeding. In our study increased Child, MELD, AIMS56, and Sofa scores were risk factors for early rebleeding, as was stated by Goldis et al. ${ }^{13}$

\section{Follow-up of Studied Patients after 6 Months}

Higher numbers of blood/blood product units transfused in the current study were significantly associated with increased mortality, as noted by the research of both Al-Freah et al, ${ }^{19}$ and Triantos et al. ${ }^{20}$ However Gado et al, ${ }^{11}$ did not record such a finding in their study.

The present study records an association between leukocytosis, increased liver transaminases and total bilirubin as well as decreased serum albumin with a higher risk of mortality. This is consistent with the findings of Cannon et al, ${ }^{21}$ and Moledina et al. ${ }^{22}$ They found that elevated leucocyte counts, serum ALT, serum total bilirubin, and a lack of endoscopy were independent mortality predictors.

There was significant difference in the prothrombin activity and the international normalized ratio (INR) in nonsurvivors, as also reported by Bishay et al.

Increased serum creatinine and urea in non survivors was significantly associated with mortality. This finding is congruent with that of Jiménez et al, ${ }^{12}$ whose study including 507 
Table 4 Clinical and laboratory data in patients after 6 months

\begin{tabular}{|c|c|c|c|c|c|}
\hline & & \multicolumn{2}{|c|}{ Outcome after 6 months } & \multicolumn{2}{|r|}{$t$-test } \\
\hline & & Died & Alive & $T$ & $p$-Value \\
\hline \multirow[t]{2}{*}{ Hemoglobin } & Range & $6.4-11.5$ & $6.1-10.5$ & 1.067 & 0.289 \\
\hline & Mean \pm SD & $8.690 \pm 1.147$ & $8.414 \pm 0.990$ & & \\
\hline \multirow[t]{2}{*}{ WBCs } & Range & $2.5-23.9$ & $2.3-24.8$ & 2.108 & $0.038^{a}$ \\
\hline & Mean \pm SD & $7.733 \pm 5.217$ & $5.705 \pm 3.263$ & & \\
\hline \multirow[t]{2}{*}{ Platelets } & Range & $40-150$ & $40-430$ & -1.569 & 0.121 \\
\hline & Mean \pm SD & $89.476 \pm 33.957$ & $109.016 \pm 53.533$ & & \\
\hline \multirow[t]{2}{*}{ ALT } & Range & $17-343$ & $10-62$ & 2.393 & $0.019^{a}$ \\
\hline & Mean \pm SD & $51.857 \pm 68.623$ & $30.531 \pm 12.623$ & & \\
\hline \multirow[t]{2}{*}{ AST } & Range & $26-245$ & $12-133$ & 2.956 & $0.004^{\mathrm{a}}$ \\
\hline & Mean \pm SD & $72.095 \pm 44.050$ & $51.797 \pm 19.134$ & & \\
\hline \multirow[t]{2}{*}{ Total bilirubin } & Range & $0.9-21$ & $0.6-8.8$ & 3.434 & $0.001^{\mathrm{a}}$ \\
\hline & Mean \pm SD & $3.905 \pm 4.246$ & $1.825 \pm 1.385$ & & \\
\hline \multirow[t]{2}{*}{ Direct bilirubin } & Range & $0.2-15.1$ & $0.2-5$ & 3.117 & $0.003^{\mathrm{a}}$ \\
\hline & Mean \pm SD & $2.319 \pm 3.156$ & $0.988 \pm 0.801$ & & \\
\hline \multirow[t]{2}{*}{ Serum albumin } & Range & $2-3.4$ & $2-4.1$ & -4.966 & $<0.001^{a}$ \\
\hline & Mean \pm SD & $2.571 \pm 0.345$ & $3.094 \pm 0.439$ & & \\
\hline \multirow[t]{2}{*}{ INR } & Range & $1.03-3.4$ & $1-2.2$ & 3.511 & $0.001^{\mathrm{a}}$ \\
\hline & Mean \pm SD & $1.586 \pm 0.611$ & $1.258 \pm 0.252$ & & \\
\hline \multirow[t]{2}{*}{ Prothrombin activity } & Range & 24-95 & $34-100$ & -2.636 & $0.010^{\mathrm{a}}$ \\
\hline & Mean \pm SD & $65.214 \pm 24.094$ & $77.438 \pm 16.238$ & & \\
\hline \multirow[t]{2}{*}{ Serum creatinine } & Range & $0.6-2.6$ & $0.6-2$ & 2.991 & $0.004^{\mathrm{a}}$ \\
\hline & Mean \pm SD & $1.227 \pm 0.458$ & $0.974 \pm 0.287$ & & \\
\hline \multirow[t]{2}{*}{ Urea } & Range & $24-220$ & $20-154$ & 3.130 & $0.002^{\mathrm{a}}$ \\
\hline & Mean \pm SD & $64.095 \pm 50.075$ & $39.906 \pm 21.165$ & & \\
\hline
\end{tabular}

Abbreviations: ALT, alanine transaminase; AST, aspartate transaminase; INR, international normalized ratio; SD, standard deviation.

astatistically significant.

patients with GI bleeding, found that high creatinine levels were independent risk factors for rebleeding of variceal and nonvariceal upper GI bleeding.

In this study, Child-Pugh score was more predictive of mortality than MELD score after 6 months. This finding was in disagreement with Hassanien et $\mathrm{al}^{, 23}$ who found that MELD scores were more predictive of mortality than the Child-Pugh scores in HCC patients with bleeding varices, it may be explained by poor hepatic reserve as indicated by Child class $C$ and higher MELD score, advanced tumor stage of patients, higher portal venous pressure, presence of more complications of liver cirrhosis, and associated major comorbidity.

\section{Conclusion}

High MELD, AIMS56, APACHE II, and ROCKall scores were risk factors for mortality after acute variceal bleeding. High death rate during the first 6 weeks is associated with anemia, hypotension, thrombocytopenia, increased serum creatinine, and INR. Decreased survival at 6 months is associated with increased Child score, presence of ascites, and associations such as hepatic encephalopathy and spontaneous bacterial peritonitis.

\section{Recommendations}

- We recommend use of prognostic scores, in particular the Rockall score for prediction of mortality after a first attack of variceal bleeding.

- Patients with high serum creatinine, low serum albumin, and high Child scores should be monitored carefully following variceal hemorrhage as they have lower survival rates.

- We suggest adding points to the MELD score for patients with advanced liver disease and those on liver transplantation waiting list when they experience a variceal bleed.

\section{Conflict of Interest}

None declared. 


\section{References}

1 Laine L. Clinical practice. Upper gastrointestinal bleeding due to a peptic ulcer. N Engl J Med 2016;374(24):2367-2376

2 Carbonell N, Pauwels A, Serfaty L, Fourdan O, Lévy VG, Poupon R. Improved survival after variceal bleeding in patients with cirrhosis over the past two decades. Hepatology 2004;40(3):652-659

3 Balanzó J, Such J, Sainz S, et al. Long term survival and severe rebleeding after variceal sclerotherapy. Surg Gynecol Obstet 1990;171(6):489-492

4 Sostres C, Lanas A. Epidemiology and demographics of upper gastrointestinal bleeding: prevalence, incidence, and mortality. Gastrointest Endosc Clin N Am 2011;21(4):567-581

5 Reynold JA, Durazo FA. Endoscopic Therapy for Esophageal Variceal Hemorrhage. In: Cameron JL, Cameron AM, eds. Current Surgical Therapy, 12th ed. Philadelphia, PA: Elsevier; 2017:339

6 Carey WD. Predictors of variceal bleeding: solving the puzzle. Am J Gastroenterol 1990;85(10):1426-1427

7 Bambha K, Kim WR, Pedersen R, Bida JP, Kremers WK, Kamath PS. Predictors of early re-bleeding and mortality after acute variceal haemorrhage in patients with cirrhosis. Gut 2008;57(6):814-820

8 Vuachet D, Cervoni JP, Vuitton L, et al. Improved survival of cirrhotic patients with variceal bleeding over the decade 2000-2010. Clin Res Hepatol Gastroenterol 2015;39(1):59-67

9 Fortune BE, Garcia-Tsao G, Ciarleglio M, et al. Vapreotide Study Group. Child-Turcotte-Pugh class is best at stratifying risk in variceal hemorrhage: analysis of a US multicenter prospective study. J Clin Gastroenterol 2017;51(5):446-453

10 de Franchis R; Baveno VI Faculty. Expanding consensus in portal hypertension: report of the Baveno VI Consensus Workshop: stratifying risk and individualizing care for portal hypertension. J Hepatol 2015;63(3):743-752

11 Gado A, Ebeid B, Abdelmohsen A, et al. Predictors of mortality in patients with acute upper gastrointestinal hemorrhage who underwent endoscopy and confirmed to have variceal hemorrhage. Alexandria Journal of Medicine 2015;51:295-304

12 Jiménez-Rosales $R$, Valverde-López $F$, Vadillo-Calles $F$, Martínez-Cara JG, López de Hierro M, Redondo-Cerezo E. Inhospital and delayed mortality after upper gastrointestinal bleeding: an analysis of risk factors in a prospective series. Scand J Gastroenterol 2018;53(6):714-720

13 Goldiş A, Lupuşoru R, Lazar D. Clinical features, endoscopic management and outcome of patients with non-variceal upper digestive bleeding by Dieulafoy lesion. Biol Med (Aligarh) 2017;9:4

14 Komori K, Kubokawa M, Ihara E, et al. Prognostic factors associated with mortality in patients with gastric fundal variceal bleeding. World J Gastroenterol 2017;23(3):496-504

15 Min YW, Lim KS, Min BH, et al. Proton pump inhibitor use significantly increases the risk of spontaneous bacterial peritonitis in 1965 patients with cirrhosis and ascites: a propensity score matched cohort study. Aliment Pharmacol Ther 2014;40(6):695-704

16 Dultz G, Piiper A, Zeuzem S, Kronenberger B, Waidmann O. Proton pump inhibitor treatment is associated with the severity of liver disease and increased mortality in patients with cirrhosis. Aliment Pharmacol Ther 2015;41(5):459-466

17 Saltzman JR, Tabak YP, Hyett BH, Sun X, Travis AC, Johannes RS. A simple risk score accurately predicts in-hospital mortality, length of stay, and cost in acute upper GI bleeding. Gastrointest Endosc 2011;74(6):1215-1224

18 Mohammad AN, Morsy KH, Ali MA. Variceal bleeding in cirrhotic patients: what is the best prognostic score? Turk J Gastroenterol 2016;27(5):464-469

19 Al-Freah MA, Gera A, Martini S, et al. Comparison of scoring systems and outcome of patients admitted to a liver intensive care unit of a tertiary referral centre with severe variceal bleeding. Aliment Pharmacol Ther 2014;39(11): 1286-1300

20 Burroughs AK, Triantos CK. Predicting failure to control bleeding and mortality in acute variceal bleeding. J Hepatol 2008;48(2):185-188

21 Cannon CP, McCabe CH, Wilcox RG, Bentley JH, Braunwald E. Association of white blood cell count with increased mortality in acute myocardial infarction and unstable angina pectoris. OPUS-TIMI 16 Investigators. Am J Cardiol 2001;87(5):636-639

22 Moledina SM, Komba E. Risk factors for mortality among patients admitted with upper gastrointestinal bleeding at a tertiary hospital: aprospective cohort study Moledina and Komba BMC. Gastroenterology 2017;17:165

23 Bishay K, Tandon P, Fisher S, et al. Clinical factors associated with mortality in cirrhotic patients presenting with upper gastrointestinal bleeding. J Can Assoc Gastroenterol 2019;1-8. DOI: $10.1093 / \mathrm{jcag} / \mathrm{gwy} 075$

24 Hassanien M, El-Talkawy MD, El-Ghannam M, El Ray A, Ali AA, Taleb HA. Predictors of in-hospital mortality in patients with hepatocellular carcinoma and acute variceal bleeding. Electron Physician 2015;7(6):1336-1343 